\title{
IMPACTO DA MATRIZ CURRICULAR VIGENTE PARA OS CURSOS TÉCNICOS EM AQUICULTURA DO IFCE: ESTUDO DE CASO NO CAMPUS ARACATI.
}

\author{
Glacio Souza Araujo ${ }^{1}$, Eduardo de Lima Melo ${ }^{1}$ \\ ${ }^{1}$ Instituto Federal de Educação, Ciência e Tecnologia do Ceará - IFCE \\ <glacio@ifce.edu.br><eduardo.melo@ifce.edu.br> \\ DOI: <https://doi.org/10.21439/conexoes.v14i4.1531>
}

\begin{abstract}
Resumo. O presente trabalho visa realizar uma comparação entre os índices de levantamento dos discentes do Curso Técnico em Aquicultura do IFCE, campus Aracati, comparando os dados de duas matrizes curriculares, sendo uma anterior (utilizada até o semestre de 2014.1) e outra vigente (utilizada a partir de 2014.2). A avaliação da matriz curricular do IFCE, campus Aracati foi feita mediante a verificação da situação atual dos discentes que ingressaram desde o semestre de 2011.2, quando se utilizou uma matriz curricular até o semestre de 2014.1, comparando-se esses dados com a matriz curricular unificada, utilizada a partir de 2014.2 até o semestre atual (2017.1). Foi observado que a forma de ensino atual (concomitante) não é eficiente devido a menor demanda de público e aprendizado. Até o semestre 2014.1, foram formadas seis turmas, com 35 discentes concludentes ou concluídos comparado com duas turmas formadas e 23 discentes concludentes ou concluídos. O Curso Técnico em Aquicultura do IFCE, campus Aracati, utilizando a matriz curricular vigente até o semestre de 2014.1, apresentou apenas 5,83 discentes concludentes/concluídos por turma em comparação a 11,50 alunos concludentes/concluídos quando passou a funcionar com a nova matriz aprovada para 2014.2, mostrando, portanto, um melhor desempenho dos discentes.
\end{abstract}

Palavras-chaves: Avaliação curricular. Educação profissional. Formação técnica. Gestão. Matriz curricular.

\begin{abstract}
The present work aims to compare the survey indexes of the students of the Technical Course in Aquaculture of the IFCE, Campus Aracati, comparing the data of two curricular matrices, one previous (used until the 1st semester/2014) and another current (in the 2nd semester/2014). The evaluation of the curricular matrix of the IFCE, Campus Aracati was done by verifying the current situation of the students who entered since the semester of $2^{\text {nd }}$ semester/2011, when a curricular matrix was used until the semester of $1^{\text {st }}$ semester/2014, comparing these data with the unified curricular matrix, used in the $2^{\text {nd }}$ semester/2014 until the semester of $1^{\text {st }}$ semester/2017. The study observed that the current teaching method (concurrent) is not efficient, due to lower public demand and learning output. Up to the $1^{\text {st }}$ semester of 2014, a total of six graduating classes were formed, totaling 35 graduating or graduated students, compared to two classes and 23 graduating or graduated students thereafter. Under these conditions, the Technical Degree in Aquiculture at IFCE, Aracati campus totaled only 5.83 graduating/graduated students per class while applying the curriculum used until the $1^{\text {st }}$ semester/2014, compared to 11.50 graduating/graduated students starting in the $2^{\text {nd }}$ semester/2014 (current curriculum, showing a better performance of the students when using this curricular matrix.
\end{abstract}

Keywords: Curriculum evaluation. Professional education. Technical training. Management. Curriculum. 


\section{INTRODUÇÃO}

O presente trabalho visa realizar uma comparação entre os índices de levantamento dos discentes do Curso Técnico em Aquicultura do Instituto Federal de Educação, Ciência e Tecnologia - IFCE, campus Aracati, comparando os dados de duas matrizes curriculares, sendo uma anterior (utilizada até o semestre de 2014.1) e outra vigente (a partir do semestre 2014.2), unificada para os cursos técnicos dos campi Acaraú, Aracati e Morada Nova, através de dados obtidos do sistema acadêmico da referida instituição de ensino.

Os dados são importantes para realizar possíveis ajustes na matriz curricular vigente e adequá-la à situação atual da aquicultura na região leste cearense, visando também a permanência, êxito e sucesso profissional dos discentes, além da minimização da evasão escolar, nesta área de ensino.

A necessidade de modificação, que contempla o ensino, a pesquisa e a extensão do Curso Técnico em Aquicultura do IFCE no campus Aracati, é um dos objetivos específicos da realização desse trabalho. Também merece destaque direcionar uma matriz curricular adequada à realidade local, voltada também para o futuro profissional técnico em aquicultura, sendo de extrema importância essa modificação.

\section{FUNDAMENTAÇÃO}

Para que se atualize determinada matriz curricular, é necessário inserir as definições de suas habilidades e competências em uma área de estudo, o que inclui a aquicultura. A seguir está definido a definição e importância desse segmento produtivo, bem como sua produção mundial e nacional.

\subsection{Importância e produção da aquicultura}

Há muitos anos, a aquicultura vem sendo apontada como a solução mais viável de suprimento de pescado para atender sua crescente demanda mercadológica devido à redução constante da oferta de recursos naturais disponíveis (BOYD; TUCKER, 1998).

O desenvolvimento da aquicultura tem contribuído para a redução do extrativismo e da pesca predatória e repercutido, de forma positiva, na preservação de diversos ecossistemas (ROCZANSKI; COSTA; BOLL, 2000). O cultivo de organismos aquáticos está em plena expansão no mundo e, no Brasil, vem contribuindo para reduzir os problemas sociais e econômicos gerados pelo declínio da pesca extrativista (ASSAD; BURSZTYN 2000).
No Brasil, com relação à aquicultura, é fundamental o conhecimento das potencialidades que podem ser exploradas para avançar no desenvolvimento dessa atividade, assim como identificar os principais problemas enfrentados pelo setor aquícola (OSTRENSKY; BORGHETTI; SOTO, 2008).

A produção aquícola nacional, em 2014, alcançou 600 mil toneladas de pescado, sendo representada por 486 mil toneladas de peixes, 90 mil toneladas de camarão, 20 mil toneladas de mexilhões e uma estimativa de 4 mil toneladas de outras espécies (ostras, camarão de água doce, peixes marinhos e algas marinhas). A tilápia lidera a produção com cerca de 260 mil toneladas, produzidas principalmente nas regiões Nordeste, Sudeste e Sul, seguido pelos peixes redondos, como os tambaquis (186 mil toneladas) e camarões marinhos (90 mil toneladas), produzidos principalmente na região Nordeste. O Estado do Ceará é o principal produtor com 42 mil toneladas, seguido do Rio Grande do Norte (KUBITZA. 2015).

Com toda essa importância, o IFCE, campus Aracati vem ofertando o Curso Técnico em Aquicultura, desde 2011, formando profissionais para atuarem em diversas áreas produtivas no município, bem como em toda a região leste cearense. A seguir, segue alguns dados da importância dessa instituição de ensino para a região leste cearense e suas especificidades.

\subsection{O IFCE, campus Aracati}

Inaugurado em primeiro de fevereiro de 2010, como campus avançado de Fortaleza, a sede do IFCE em Aracati iniciou sua atuação com a oferta dos cursos técnicos de Agenciamento de Viagens, Aquicultura e Informática. A primeira sede funcionou nas instalações do Centro Vocacional Tecnológico da cidade. E foi de lá que a unidade conseguiu passar dos 80 alunos inicialmente matriculados para mais de mil estudantes atendidos em sete anos de atividade. Atualmente, possui sede própria inaugurada em 19/08/2016.

O IFCE, campus Aracati está equipado com cinco grupos de pesquisa nas mais diversas áreas de domínio:

(i) Química,

(ii) Letras

(iii) Geografia

(iv) Zootecnia e Recursos Pesqueiros e

(v) Tecnologia da Informação, 
com trabalhos nas áreas de ensino, pesquisa e extensão voltados ao desenvolvimento do interior cearense.

Possui 4 cursos de graduação, 4 cursos técnicos, 1 técnico integrado ao ensino médio e 1 mestrado profissional (Bacharelado em Engenharia de Aquicultura, Bacharelado em Ciências da Computação, Licenciatura em Química e Tecnólogo em Hotelaria; Técnico em Aquicultura, Eventos, Guia de Turismo e Informática; Integrado em Petroquímica e Mestrado Profissional em Ciência da Computação, respectivamente). A estrutura física contempla um bloco administrativo, laboratórios de informática, um bloco de ensino (com todas as salas de aula climatizadas) e diversos laboratórios, beneficiando, atualmente, mais de 800 alunos.

A biblioteca do IFCE, campus Aracati é especializada de acordo com os cursos ministrados no campus, contando com um acervo de 2.500 materiais entre livros, periódicos e CD's, laboratórios multimídia, salas de estudo e acesso à base de dados e periódicos da CAPES. Seu quadro de funcionários, contando com servidores e professores, chega a mais de 50 pessoas. Nesse contexto, tem mantido parcerias nacionais e internacionais, pela qual se processa a integração das diversas áreas de conhecimento e potencializa sua produção em áreas onde existe carência de pesquisadores pertencentes à equipe institucional.

Tem um periódico próprio on-line desde 2011, revista Conexões - Ciência e Tecnologia, com tiragem quadrimestral nos meses de março, julho e novembro, que é uma publicação da rede, a nível de instituição, no Estado do Ceará.

Os discentes do campus Aracati são provenientes, em sua grande maioria, do litoral leste do estado do Ceará. Dessa forma, são recebidos alunos de Beberibe, Fortim e Icapuí, municípios estes que exploram, principalmente, o turismo e a aquicultura, vislumbrando na formação profissional o futuro das suas economias. Além dos alunos das regiões litorâneas, ainda são beneficiados os discentes do baixo Jaguaribe, provenientes das cidades de Palhano, Jaguaruana e Itaiçaba, o que demonstra que a zona de influência do campus Aracati e os benefícios gerados pela interiorização do ensino são capazes de irradiar para áreas circunvizinhas.

O município de Aracati reúne condições ambientais favoráveis para o desenvolvimento de atividades aquícolas, ou seja, a produção de organismos aquáticos tropicais, principalmente o cultivo de peixes (piscicultura), camarões (carcinicultura), algas (algicultura), moluscos (malacocultura), entre outras atividades. Esta região apresenta elevado potencial hídrico (mar, estuários, rios, lagos e lagoas), clima com temperaturas mé- dias acima de $26{ }^{\circ} \mathrm{C}$ o ano todo e elevada insolação, tornando-a ainda mais promissora nessa atividade. A região abrange uma quantidade significativa de empreendimentos aquícolas, destacando-se o cultivo do camarão marinho Litopenaeus vannamei, que contribui de forma significativa para a geração de emprego, renda e melhoria da qualidade de vida das comunidades locais.

Desde a sua implantação no município de Aracati, o campus vem ofertando o Curso Técnico em Aquicultura, o qual tem contribuído para a formação profissional e tecnológica na região, através da inserção de técnicos no mercado de trabalho. O IFCE, na sua política, visa à implementação de cursos, buscando sempre a melhoria na qualidade da oferta deles. Nesse contexto, houve a necessidade de expansão dessa área de atuação (aquicultura) através de um curso de nível superior visando à formação de profissionais cada vez mais qualificados, elevando-se, assim, a qualidade na educação. Este curso é o Bacharelado em Engenharia de Aquicultura, com carga horária total de 3.600 h, já em funcionamento com a primeira turma (formada por 32 alunos matriculados) desde o semestre de 2017.1.

Segundo dados do IFCE em números, que é uma ferramenta de acesso público disponível na internet, a qual apresenta dados unificados e padronizados conceitualmente - relevantes para balizar a tomada de decisões estratégicas no âmbito do IFCE - e reúne as informações de diferentes dados acadêmicos relacionados à atuação dessa instituição de ensino, no semestre de 2017.1, estão matriculados 155 discentes no Curso Técnico em Aquicultura do campus Aracati (<http://ifceemnumeros.ifce.edu.br/>).

Como dever do IFCE, a atualização de matrizes curriculares é importante para elevar os índices de permanência e êxito, minimizando, consequentemente, a evasão escolar, que engloba toda a comunidade acadêmica nessa ação. Para que se possa ter argumentos para a atualização de matrizes curriculares é necessário também um embasamento teórico sobre Projeto PolíticoPedagógico, que será descrito a seguir.

\subsection{Projeto Político-Pedagógico}

O Projeto Político-Pedagógico é a sistematização de um processo de planejamento participativo, que define claramente o tipo de ação educativa que se quer realizar, para a intervenção e mudança da realidade, envolvendo uma construção coletiva de conhecimento (VASCONCELLOS, 1996).

Para a construção coletiva de um Projeto PolíticoPedagógico visando à educação de qualidade, é necessário que efetivamente a escola reúna pessoas as quais 
interajam entre si e opere por meio de estruturas e processos organizativos próprios, a fim de alcançar os objetivos e se enquadre num espaço onde todos os segmentos estejam engajados e comprometidos com a elaboração de todo o processo pedagógico. Assim, todos os agentes participantes desse processo educacional devem estar envolvidos (LIBÂNEO, 2004).

Diante disso, é de grande importância a participação de todos os atores da instituição na busca de melhorias em uma matriz curricular, que compreende, em primeiro lugar, o perfil desejado dos egressos e deste emerge a concepção filosófica, pedagógica e metodológica do curso (CATAPAN; KASSICK; OTERO, 2016), especificamente do Curso Técnico em Aquicultura do IFCE, campus Aracati.

Para que haja participação efetiva no planejamento, deve-se reunir o máximo de pessoas envolvidas no processo, visando alcançar as metas desse planejamento, com as devidas necessidades educativas, tornando a escola dinâmica na medida em que toda a comunidade escolar se integra num entendimento mútuo, onde os alunos são levados a participarem de todas as atividades elaboradas pela mesma (LUCK, 2008).

Do ponto de vista educacional, o planejamento expõe o que se deseja realizar e o que se pretende atingir, identificando as dificuldades e procurando corrigilas (VASCONCELLOS, 1996).

Nessas condições, é destacável a importância de se planejar em conjunto, não apenas por um pequeno grupo de pessoas, pois uma determinada pessoa - ao apresentar suas dificuldades e especificidades - poderão ser otimizadas com a participação de todo o grupo de pessoas no planejamento. É importante mencionar a análise reflexiva de cada participante, objetivando destacar suas potencialidades e dificuldades no planejamento. Esses dados são importantes para ter mecanismos de modificar uma matriz curricular e, consequentemente, um Projeto Político-Pedagógico, visando acima de tudo a aprendizagem dos discentes, pois aprender, segundo Boimare (1999), é uma aventura, ao mesmo tempo excitante e psicologicamente perigosa.

O ser humano não pode viver sem aprender e, quando aprende, às vezes, não obtém êxito, e uma série de fatores podem estar envolvidos nesse contexto, como família, relações interpessoais, não identificação com determinada área dentre outras, sendo esse insucesso escolar um problema importante nas sociedades contemporâneas (IRELAND, 2007).

Visando à minimização desse insucesso escolar no Curso Técnico em Aquicultura do IFCE, campus Aracati, a atualização do Projeto Político-Pedagógico é ne- cessária, fazendo com que os indicadores de permanência e êxito sejam mais elevados e os egressos tenham destaque no mercado de trabalho.

Segundo Hypolito (2014), pensar o trabalho pedagógico significa pensar o currículo, não apenas o conteúdo programático, mas tudo o que organiza a vida escolar, implicando em trabalho coletivo, havendo a necessidade de gestão democrática, o que significa o desenvolvimento de processos participativos, e para isso, é imprescindível um bom tempo de planejamento.

Diante das informações apresentadas, o presente trabalho visa realizar uma comparação entre os índices de levantamento dos discentes do Curso Técnico em Aquicultura do Instituto Federal de Educação, Ciência e Tecnologia - IFCE, campus Aracati, comparando os dados de duas matrizes curriculares, sendo uma anterior (utilizada até o semestre de 2014.1) e outra vigente (utilizada a partir de 2014.2).

\section{METODOLOGIA}

A avaliação da matriz curricular do Curso Técnico em Aquicultura do IFCE, campus Aracati foi feita mediante a verificação da situação atual dos discentes que ingressaram desde o semestre de 2011.2, quando se utilizou uma matriz curricular até o semestre de 2014.1, comparando-se esses dados com a matriz curricular unificada para os campi Acaraú, Aracati e Morada Nova, utilizada a partir de 2014.2 até o semestre 2017.1. Foi englobada a quantidade de discentes concludentes/concluídos, abandonos, trancamentos e matriculados através da utilização de dados obtidos do sistema acadêmico do referido curso. Além disso, foi verificado o coeficiente médio de rendimento dos discentes em cada turma, somando-se os valores individuais e tirando-se a média aritmética desses dados, para se comparar o rendimento deles nas duas matrizes utilizadas nesse estudo.

Os dados foram obtidos na Coordenadoria de Controle Acadêmico - CCA, do IFCE, campus Aracati, utilizando-se das informações pertinentes e verificandose também as disciplinas em que mais ocorreram reprovações no período. A pesquisa abordada no trabalho é classificada como exploratória e de campo. O procedimento utilizado foi o método de observação.

A abordagem empregada neste trabalho foi a pesquisa qualitativa, que não se preocupa com representatividade numérica, mas, sim, com o aprofundamento da compreensão de um grupo social, de uma organização (GERHARDT; SILVEIRA, 2009).

As coletas dos dados ocorreram no final do semestre letivo de 2017.1 quando mais de uma turma já concluiu 
seus estudos na matriz curricular vigente para o Curso Técnico em Aquicultura do IFCE, campus Aracati.

Os resultados adquiridos foram importantes para atualizar possíveis entraves verificados na matriz unificada do Curso Técnico em Aquicultura do IFCE, campus Aracati, visando à melhoria do ensino, ao rendimento acadêmico dos discentes, à permanência, ao êxito e ao ingresso no mercado de trabalho dos futuros egressos. A seguir são apresentados os resultados e a discussão desse trabalho.

\section{RESULTADOS E DISCUSSÃo}

\subsection{Modificações ocorridas entre as matrizes cur- riculares}

A educação é o principal mecanismo de inclusão social e principal responsável pelo desenvolvimento social de uma nação, onde o direito à educação pública deve ser a universalização com qualidade (SANTOS; ALVES, 2011).

O IFCE, através de seu Projeto Político Institucional (IFCE, 2015a), aprovado pela Resolução do CONSUP N ${ }^{\circ} 33$, de 22 de junho de 2015, cita sua Política de Educação Profissional Técnica de Nível Médio, mencionando a relevância do ensino técnico no processo de desenvolvimento do país e na exigência da Lei $11.892 / 2008$, que cria os Institutos federais e determina que $50 \%$ das vagas dos Institutos Federais sejam destinadas à formação técnica, oferta cursos técnicos de acordo com a LDB n 9.394/96 bem como o Decreto $\mathrm{n}^{\circ}$ 5.154/2004, a Resolução n ${ }^{\circ}$ 6, de 20/09/2012, que trata sobre as Diretrizes Curriculares Nacionais para a Educação Profissional Técnica de Nível Médio além de outras regulamentações estabelecidas pelo Ministério da Educação, e de acordo com o $\S 1^{\circ}$ do art. $4^{\circ}$ do Decreto $\mathrm{n}^{0} 5.154 / 2004$, cita suas formas de oferta do ensino técnico, que podem ser: Integrada, Concomitante ou Subsequente.

Além desse Projeto Político Institucional, merece destaque acrescentar o Regulamento da Organização Didática (IFCE, 2015b), aprovado pela Resolução do CONSUP $N^{\circ} 35$, de 22 de junho de 2015, na Seção II, art. $5^{\circ}$, mencionado que os cursos a serem ofertados por cada campus deverão constar no Plano Anual de Ações (PAA), o qual é construído em consonância com o Plano de Desenvolvimento Institucional (PDI) e, ainda, possuírem ato autorizativo expedido pelo Conselho Superior do IFCE (CONSUP).

Em Aracati, o Curso Técnico em Aquicultura foi aprovado para funcionamento, ad referendum, pelo Conselho Superior do Instituto Federal de Educação,
Ciência e Tecnologia do Ceará, segundo a Resolução $\mathrm{N}^{\mathrm{o}}$ 027, de 13 de agosto de 2010, considerando o que determina o art. $2^{\circ}, \S 3^{\circ}$, da Lei $\mathrm{N}^{\mathrm{o}} 11.892$, de 29/12/2008 (DOU 30/12/2018).

A modificação curricular partiu do Pró-Reitor de Ensino do Instituto Federal de Educação, Ciência e Tecnologia do Ceará, no uso de suas atribuições, considerando a Portaria No 298, de 12 de março de 2013 e a Portaria N ${ }^{\mathrm{o}} 200 / \mathrm{GR}$, de 28 de fevereiro de 2014, emitiu a Portaria $N^{\circ}$ 026/2015/PROEN, de 29 de abril de 2015, criando a comissão para o alinhamento das Matrizes dos Cursos Técnicos em Aquicultura do IFCE, conforme Nota Técnica 001-2014-PROEN, determinando um valor mínimo de similaridade de disciplinas entre as matrizes de $70 \%$, ficando o restante relacionadas ao currículo do egresso respeitando as especificidades da região, composta por Coordenadores e professores desses cursos nos campi Acaraú, Aracati e Morada Nova, conforme a Figura 1 .

Figura 1: Portaria $N^{0} 026 / 2015 / P R O E N$, de 29 de abril de 2015, criando a comissão para o alinhamento das Matrizes dos Cursos Técnicos em Aquicultura do IFCE.

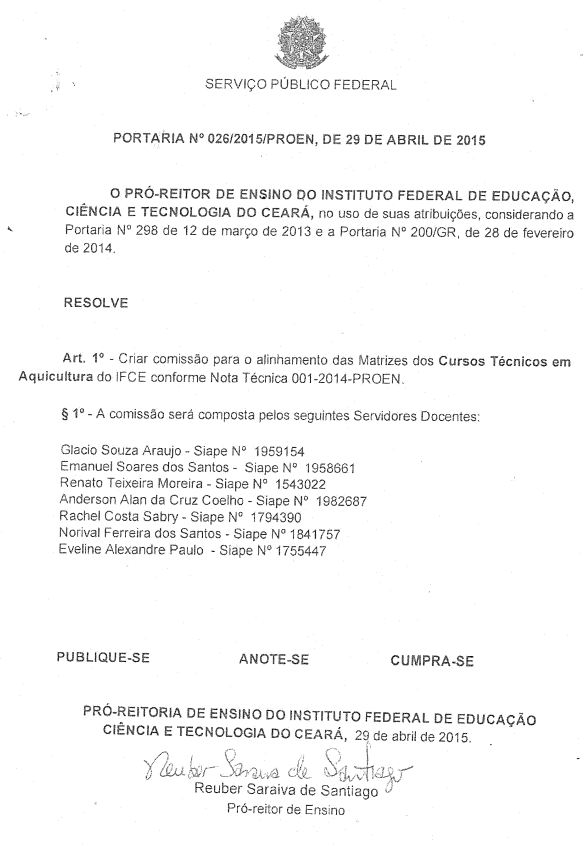

A matriz curricular do Curso Técnico em Aquicul- 
tura utilizada desde o semestre de 2011.2 até o semestre de 2014.1 pode ser vista na Tabela 1 . Na Tabela 2 se encontra a matriz curricular utilizada a partir do semestre 2014.2, unificada para os Cursos Técnicos do IFCE dos campi Acaraú, Aracati e Morada Nova.

Para avaliar o impacto da matriz curricular vigente nos Cursos Técnicos em Aquicultura do IFCE (no caso específico do campus Aracati), primeiramente, seguemse as modificações ocorridas entre a Matriz Curricular Unificada dos Cursos Técnicos em Aquicultura do IFCE (campi Acaraú, Aracati e Morada Nova), utilizada desde o período de 2014.2, com a Matriz Curricular do Curso Técnico em Aquicultura utilizada até o semestre de 2014.1.

MUDANÇA 01 - Alteração do nome da disciplina Português Instrumental ( $2^{\circ}$ semestre na matriz antiga) para Português, no $1^{\circ}$ Semestre na matriz nova. No primeiro semestre, também foi alterado o nome da disciplina Informática Aplicada, para Informática.

MUDANÇA 02 - Alteração da carga horária da disciplina Matemática Aplicada, que na matriz antiga era de 80 h, e na matriz nova será apenas de 40 h, tendo o nome passado apenas para Matemática.

MUDANÇA 03 - Inclusão das disciplinas de Química e Higiene e Segurança do trabalho, ambas de 40 $\mathrm{h}$ cada, no $1^{\circ}$ Semestre na matriz nova.

MUDANÇA 04 - Exclusão da disciplina Fundamentos de Oceanografia, de $40 \mathrm{~h}$, contida no $1^{\mathrm{o}}$ semestre na matriz antiga.

MUDANÇA 05 - Alteração da carga horária da disciplina Fisiologia de Organismos Aquáticos, que, na matriz antiga, era de $80 \mathrm{~h}$ e, na matriz nova, é apenas de 40 h. Houve também a reposição dela, saindo do $1^{\circ}$ semestre e passando para o $2^{\circ}$ semestre na matriz nova.

MUDANÇA 06 - Alteração da disciplina Limnologia Aplicada para Qualidade de Água na Aquicultura, mas mantendo sua carga horária $(40$ h) e o semestre no qual já estava alocada ( $2^{\circ}$ semestre na matriz).

MUDANÇA 07 - Alteração da disciplina de Princípios da Nutrição e Patologia na Aquicultura para Enfermidades em Organismos Aquáticos Cultivados, mas mantendo sua carga horária ( 80 h) e o semestre no qual já estava alocada ( $2^{\circ}$ semestre na matriz).

MUDANÇA 08 - Realocação da disciplina Legislação Aplicada à Aquicultura $\left(3^{\circ}\right.$ semestre na matriz antiga) para o $2^{\circ}$ Semestre na matriz nova, mas mantendo sua carga horária $(40 \mathrm{~h})$.

MUDANÇA 09 - Inclusão da disciplina Fundamentos de Economia e Comercialização, de $40 \mathrm{~h}$, no segundo semestre da matriz nova.

MUDANÇA 10 - Alteração da disciplina Processa- mento do Pescado I para Beneficiamento do Pescado, bem como da sua carga horária, que, na matriz anterior, era de 40 h e, na matriz nova, será de 80 h.

MUDANÇA 11 - Exclusão da disciplina Microbiologia do Pescado $(40 \mathrm{~h})$ presente no segundo semestre da matriz antiga.

MUDANÇA 12 - Junção das disciplinas Piscicultura Marinha, Cultivo de Moluscos e Cultivo de Macroalgas, ambas do terceiro semestre na matriz antiga, na disciplina Aquicultura Marinha (40 h).

MUDANÇA 13 - Modificação do nome da disciplina Aquicultura de Água Doce para Aquicultura Continental, além da redução de sua carga horária, de $80 \mathrm{~h}$ para $40 \mathrm{~h}$, na matriz nova.

MUDANÇA 14 - Criação da disciplina Tilapicultura, de $80 \mathrm{~h}$, no terceiro semestre na matriz nova.

MUDANÇA 15 - Criação da disciplina Produção de Alimento Vivo para a Aquicultura, de 40 h, no terceiro semestre na matriz nova.

MUDANÇA 16 - Modificação do nome da disciplina Processamento do Pescado II para Controle de Qualidade do Pescado, além da elevação de sua carga horária, de $40 \mathrm{~h}$ para $80 \mathrm{~h}$, na matriz nova.

MUDANÇA 17 - Criação da disciplina Empreendedorismo, de 40 h, no quarto semestre da matriz nova, juntamente com a disciplina de Estágio Supervisionado (300 h).

(SANTO, 2006), em seu trabalho sobre a análise da mudança na matriz curricular do Curso de Comunicação Social numa instituição de ensino superior cita que essas instituições de ensino deparam-se com um desafio constante, que é a manutenção de suas matrizes curriculares de maneira que atendam às demandas da sociedade, cumpram as diretrizes curriculares estabelecidas pelo Ministério da Educação e, por fim, mantenham a sustentabilidade financeira dos seus programas.

\subsection{Rendimento acadêmico e situação dos discen- tes entre as matrizes curriculares}

A Tabela 3 mostra a comparação da situação dos discentes na Matriz Curricular do Curso Técnico em Aquicultura do IFCE, campus Aracati até o semestre de 2014.1 e a matriz vigente, unificada e utilizada a partir do semestre de 2014.2.

Como podemos observar, a modalidade de ensino do Curso Técnico em Aquicultura do IFCE, campus Aracati que utilizou a matriz curricular até o semestre de 2014.1 foi subsequente, ou seja, somente para pessoas que já tem o Ensino Médio completo. Porém, a partir do semestre de 2014.2, que passou a utilizar a 
Tabela 1: Matriz Curricular do Curso Técnico em Aquicultura utilizada até o semestre de 2014.1.

\begin{tabular}{|c|c|c|c|}
\hline Semestre & Disciplina & Créditos & Horas \\
\hline \multirow{7}{*}{1} & Informática Aplicada & 2 & 40 \\
\hline & Matemática Aplicada & 4 & 80 \\
\hline & Educação Ambiental & 2 & 40 \\
\hline & Introdução à Aquicultura & 2 & 40 \\
\hline & Biologia Aquática & 4 & 80 \\
\hline & Fisiologia de Organismos Aquáticos & 4 & 80 \\
\hline & Fundamentos de Oceanografia & 2 & 40 \\
\hline & Total $1^{\circ}$ Semestre & 20 & 400 \\
\hline \multirow{7}{*}{2} & Limnologia Aplicada & 2 & 40 \\
\hline & Microbiologia do Pescado & 2 & 40 \\
\hline & Extensão Pesqueira e Aquícola & 2 & 40 \\
\hline & Processamento do Pescado I & 4 & 80 \\
\hline & Princípios da Nutrição e Patologia na Aquicultura & 4 & 80 \\
\hline & Português Instrumental & 4 & 80 \\
\hline & Construções para Aquicultura & 2 & 40 \\
\hline \multirow{9}{*}{3} & Total $2^{\circ}$ Semestre & 20 & 400 \\
\hline & Piscicultura Marinha & 2 & 40 \\
\hline & Aquicultura de Água Doce & 4 & 80 \\
\hline & Cultivo de Moluscos & 2 & 40 \\
\hline & Cultivo de Macroalgas & 2 & 40 \\
\hline & Carcinicultura & 4 & 80 \\
\hline & Processamento do Pescado II & 2 & 40 \\
\hline & Legislação Aplicada à Aquicultura & 2 & 40 \\
\hline & Relações Interpessoais e Ética & 2 & 40 \\
\hline \multicolumn{2}{|r|}{ Total $3^{\circ}$ Semestre } & 20 & 400 \\
\hline 4 & Estágio Supervisionado & 15 & 300 \\
\hline \multirow{2}{*}{\multicolumn{2}{|c|}{$\begin{array}{c}\text { Total } 4^{\circ} \text { Semestre } \\
\text { TOTAL DO CURSO }\end{array}$}} & 15 & 300 \\
\hline & & 75 & 1500 \\
\hline
\end{tabular}

Fonte: Projeto Político-Pedagógico do Curso Técnico em Aquicultura do IFCE, campus Aracati.

matriz vigente (unificada), a modalidade foi concomitante, ou seja, para pessoas que estão cursando o ensino médio. Vale salientar que, em ambas as matrizes, ocorre ingresso de discentes nos turnos matutino e vespertino, alternando-os em cada semestre letivo, sendo essas ofertas segundo decisão interna entre os docentes do eixo de Recursos Naturais, que contempla o Curso Técnico em Aquicultura do IFCE campus Aracati.

De uma forma geral, no ensino técnico integrado ao ensino médio, a demanda por vagas é alta, e a taxa de evasão é baixa, onde, o aluno costuma ser adolescente ainda, muitas vezes está estudando o médio e o técnico juntos, pressionado pela família, que não permite que ele pare de estudar para trabalhar sem concluir o ensino médio (ARAÚJO, 2013).

Ainda segundo Araújo (2013), nas formas de oferta concomitante e subsequente, a evasão é mais comum, pois o aluno tem pressa em conseguir um emprego, mas, quando consegue uma certificação intermediária, vai trabalhar, abandonando o técnico e aumentando as taxas de evasão.

No caso específico do Curso Técnico em Aquicultura do IFCE, campus Aracati, comparando as suas duas formas de oferta, a maior evasão foi observada na matriz anterior, com modalidade subsequente, em que o aluno para de estudar para trabalhar sem concluir o curso, em virtude da relativa oferta de vagas no setor produtivo da região. Porém, também é observada a grande evasão na matriz em vigência (concomitante), que, apesar de os discentes serem adolescentes ainda, estão estudando o médio e o técnico juntos e, pressionados pela família, que não o autoriza parar de estudar para trabalhar sem concluir o ensino médio. Todavia, não conseguem ter efetivo aprendizado no curso nem 

NO CAMPUS ARACATI.

Tabela 2: Matriz Curricular Unificada dos Cursos Técnicos em Aquicultura do IFCE nos campi Acaraú, Aracati e Morada Nova, utilizada a partir do semestre 2014.2.

\begin{tabular}{|c|c|c|c|}
\hline Semestre & Disciplina & Créditos & Horas \\
\hline \multirow{8}{*}{1} & Português & 4 & 80 \\
\hline & Informática & 2 & 40 \\
\hline & Matemática & 2 & 40 \\
\hline & Química & 2 & 40 \\
\hline & Biologia Aquática & 4 & 80 \\
\hline & Higiene e Segurança do Trabalho & 2 & 40 \\
\hline & Educação Ambiental & 2 & 40 \\
\hline & Introdução à Aquicultura & 2 & 40 \\
\hline \multicolumn{2}{|r|}{ Total $1^{\circ}$ Semestre } & 20 & 400 \\
\hline \multirow{8}{*}{2} & Extensão Pesqueira e Aquícola & 2 & 40 \\
\hline & Qualidade de Água na Aquicultura & 2 & 40 \\
\hline & Fisiologia de Organismos Aquáticos & 2 & 40 \\
\hline & Fundamentos de Economia e Comercialização & 2 & 40 \\
\hline & Enfermidades em Organismos Aquáticos Cultivados & 4 & 80 \\
\hline & Construções para Aquicultura & 2 & 40 \\
\hline & Legislação Aplicada à Aquicultura & 2 & 40 \\
\hline & Beneficiamento do Pescado & 4 & 80 \\
\hline \multicolumn{2}{|r|}{ Total $2^{\circ}$ Semestre } & 20 & 400 \\
\hline \multirow{7}{*}{3} & Aquicultura Marinha & 2 & 40 \\
\hline & Carcinicultura & 4 & 80 \\
\hline & Aquicultura Continental & 2 & 40 \\
\hline & Tilapicultura & 4 & 80 \\
\hline & Controle de Qualidade do Pescado & 4 & 80 \\
\hline & Produção de Alimento Vivo para Aquicultura & 2 & 40 \\
\hline & Relações Interpessoais e Ética & 2 & 40 \\
\hline \multicolumn{2}{|r|}{ Total $3^{\circ}$ Semestre } & 20 & 400 \\
\hline \multirow{2}{*}{4} & Empreendedorismo & 2 & 40 \\
\hline & Estágio Supervisionado & 15 & 300 \\
\hline \multicolumn{2}{|r|}{ Total $4^{\circ}$ Semestre } & 17 & 340 \\
\hline \multicolumn{2}{|r|}{ TOTAL DO CURSO } & 77 & 1540 \\
\hline
\end{tabular}

Fonte: Projeto Político-Pedagógico do Curso Técnico em Aquicultura do IFCE, campus Aracati.

no ensino médio, dedicando-se muitas vezes a este último e abandonando aquele.

Outro fator importante a ser observado atualmente na área da aquicultura, especificamente na carcinicultura (cultivo de camarões), muito presente na região leste cearense e setor de trabalho de quase todos egressos no curso, é a presença do Vírus da Síndrome da Mancha Branca (WSSV), que é um patógeno que tem devastado a indústria do cultivo de camarões em vários países (LIGHTNER et al., 1998) e atualmente é considerado o mais sério patógeno viral de camarões no mundo (FLEGEL, 2009). A presença do vírus durante os cultivos causa alto índice de mortalidade dos camarões em sistemas intensivos de produção, gerando perdas econômicas gigantescas e demissão de trabalhadores nas fazendas, que em muitas vezes, não tem o grau de Técnico em Aquicultura e que já concluíram o Ensino Médio, sendo uma oportunidade caso o Curso Técnico em Aquicultura seja ofertado na modalidade subsequente, nesse caso específico existente na carcinicultura.

Até o semestre 2014.1, foram formadas seis turmas, com 35 discentes concludentes ou concluídos, comparado com duas turmas formadas e 23 discentes concludentes ou concluídos. Nessas condições, o Curso Técnico em Aquicultura do IFCE, campus Aracati, utilizando a matriz curricular até o semestre de 2014.1, apresentou apenas 5,83 discentes concluden- 
Tabela 3: Comparação da situação dos discentes entre a matriz curricular do Curso Técnico em Aquicultura do IFCE no campus Aracati até o semestre de 2014.1 e a matriz vigente (unificada) a partir do semestre de 2014.2.

\begin{tabular}{lcc}
\hline \multicolumn{1}{c}{ Item } & Matriz Utilizada até & Matriz Utilizada a partir de \\
& $\mathbf{2 0 1 4 . 1}$ & $\mathbf{2 0 1 4 . 2}$ \\
\hline Modalidade & Subsequente & Concomitante \\
Número de discentes que ingressaram por semestre & 30 & 30 \\
Número de turmas concluídas & 6 & 2 \\
Número de discentes concludentes/concluídos & 35 & 23 \\
Número médio concludentes/concluídos por turma & 5,83 & 11,5 \\
Número de discentes abandonados & 1 & 5 \\
Número de discentes trancados & 1 & 9 \\
Número de discentes matriculados & 2 & 79 \\
Coeficiente médio de rendimentos dos discentes & 7,01 & 6,6 \\
Disciplinas que mais reprovaram na matriz & Matemática Aplicada & Matemática e Química \\
\hline
\end{tabular}

Fonte: Sistema Acadêmico do IFCE.

tes/concluídos por turma comparado com 11,50 alunos concludentes/concluídos a partir do semestre 2014.2 da matriz vigente e unificada para os campi Acaraú, Aracati e Morada Nova.

Com os dados apresentados, o impacto da matriz atual foi positivo, pois, apesar da menor quantidade de turmas formadas e do número de discentes concludentes ou concluídos, apresentou uma média de discentes $(11,50)$ concludentes/concluídos por turma superior a matriz anterior $(5,83)$, mais que o dobro desta, o que vem ao encontro da melhoria do ensino, pesquisa e extensão, consequentemente. Vale salientar que a maior evasão escolar foi observada quando se utilizou a matriz curricular anterior (em funcionamento até o semestre 2014.1), mostrando dados preocupantes que necessitavam ser melhorados para garantir maior permanência e êxito dos alunos no decorrer do curso. Contudo, contata-se que podem ser realizados pequenos ajustes nela visando otimizá-la ainda mais.

O insucesso escolar e a consequente evasão denotam o próprio fracasso das relações sociais as quais se expressam na realidade desumana que se vivencia no cotidiano, sendo as causas da evasão serem classificadas de acordo com os seus fatores determinantes, englobando a escola (não atrativa, autoritária, com professores despreparados, insuficiente, ausência de motivação etc.), o aluno (desinteressado, indisciplinado, com problema de saúde, gravidez etc.), pais ou responsáveis (não cumprimento do pátrio poder, desinteresse em relação ao destino dos filhos etc.) e social (trabalho com incompatibilidade de horário para os estudos, agressão entre os alunos, violência etc.) (FERREIRA, 2013).

Qualquer que seja o motivo, o abandono da escola na vida de um jovem pode trazer repercussões negati- vas ao desenvolvimento de sua vida adulta (SOARES, 2013).

Segundo Arantes (2012), alguns alunos que já trabalham e buscam uma formação técnica apresentam dificuldade em relação ao estudo, porque, mesmo que ele signifique emancipação e uma melhor perspectiva de vida, o significado do trabalho para eles que vivem num ambiente familiar com necessidades financeiras é sinônimo de sobrevivência, fato que o considera como superior ao estudo.

Existem várias possibilidades que podem levar ao trancamento da matrícula, além do abandono, e nem todas vão configurar "evasão", podendo o aluno mudar de curso; ou permanecer no mesmo curso e mudar apenas a modalidade (integrado, subsequente ou concomitante) ou a rede de ensino no qual estuda; interromper um técnico para ingressar no ensino superior ou mesmo abandonar definitivamente a formação profissional, caracterizando, dessa forma, evasão escolar (SOARES, 2013). Esta última é a mais comumente observada entre os discentes do Curso Técnico em Aquicultura do IFCE, campus Aracati.

O problema da oferta do curso na modalidade concomitante, em vigência no IFCE - campus Aracati, também tem como consequência o maior número de discentes que abandonaram ou trancaram o curso, bem superior ao número de estudantes na mesma situação na matriz anterior, na modalidade subsequente (Tabela 3). O motivo para o maior abandono ou o trancamento de curso pode estar relacionado com a dificuldade de conciliação entre o técnico e o ensino médio, verificado também nas disciplinas que tem maior número de reprovações.

A forma de oferta na modalidade concomitante tam- 
bém é problemática para o aluno que precisa repetir algum componente curricular, impossível de fazê-lo no contraturno devido à presença do aluno em sala de aula, no ensino médio, o que pode prolongar o tempo de formação deles. Isso é observado na quantidade de alunos ainda matriculados no curso, pois, nas duas turmas concluídas na matriz vigente, existe um total de quatro alunos comparado com apenas dois, na matriz utilizada até o semestre 2014.1. Essas duas matrículas vigentes são de estudantes que trabalham na área e não têm muito tempo para cursar as disciplinas regularmente; apesar disso, estão prestes a finalizar o curso.

Ainda com relação ao número de alunos matriculados, no semestre 2017.1, o número de alunos matriculados no Curso Técnico em Aquicultura, com quatro semestres em andamento, é 75, e alguns destes já concluíram todas as disciplinas e estão no estágio curricular obrigatório. Vale salientar que, em ambas as matrizes, o número de discentes que ingressaram por semestre é 30 .

Os discentes que ingressaram na matriz curricular até o semestre 2014.1 apresentaram um coeficiente médio de rendimentos de 7,01, superior aos alunos que ingressaram a partir de 2014.2, com a matriz unificada $(6,60)$.

Por fim, comparando as duas matrizes curriculares, as disciplinas que mais reprovaram os discentes foram a Matemática Aplicada (matriz curricular vigente até 2014.1) e Matemática e Química (matriz curricular unificada e em funcionamento a partir do semestre de 2014.2). Nessa matriz curricular, foi inclusa a disciplina Química, devido à necessidade dos conhecimentos a serem adquiridos nela, de grande importância para os futuros egressos.

Vale salientar que, além da disciplina de Química, também foram inclusas as disciplinas de Higiene e Segurança do Trabalho, Enfermidades em Organismos Aquáticos Cultivados, Fundamentos de Economia e Comercialização, Tilapicultura, Produção de Alimento Vivo e Empreendedorismo, dentre outras, de relevante importância para o Curso Técnico em Aquicultura do IFCE, campus Aracati. Ainda com relação às disciplinas nessa matriz vigente, existe uma necessidade de se dividir a disciplina de Aquicultura Marinha, ficando Cultivo de Moluscos, Cultivo de Macroalgas e Cultivo de Peixes Marinhos, explorando melhor esses conhecimentos, bem específicos para os futuros egressos.

A atualização do Projeto Pedagógico deve ser feito com um bom planejamento, que, para ter sentido, precisa estabelecer relação com a prática, isto é, precisa ser concebido como um processo de intervenção da re- alidade escolar, o qual envolve reflexão e tomada de decisão visando à transformação ou ao redirecionamento das ações (FERNANDES, 2013). Ainda segundo o autor, uma instituição escolar, para desenvolver uma educação de qualidade, necessita formular seus objetivos, propor ações significativas, escolher os meios e critérios para avaliá-las, e isso se torna possível por meio do processo de planejamento. Segundo Padilha (2003), o planejamento visando ao Projeto Político-Pedagógico exercita nossa capacidade de tomar decisões coletivamente.

\section{CONSIDERAÇÕES FINAIS}

O Curso Técnico em Aquicultura do IFCE, campus Aracati, até o semestre 2014.1, formou seis turmas, com 35 discentes concludentes ou concluídos, comparado à formação de duas turmas e 23 discentes concludentes ou concluídos. Nessas condições, o curso, utilizando a matriz curricular até o semestre de 2014.1, apresentou apenas 5,83 discentes concludentes/concluídos por turma em comparação a 11,50 alunos concludentes/concluídos a partir do semestre de 2014.2 quando do funcionamento da matriz vigente. Nessas condições, foi observado que a matriz curricular mais eficiente e mais atrativa é a atual, bem melhor que a anterior, apesar de se constatar que podem ser realizados pequenos ajustes nela visando otimizá-la ainda mais, como por exemplo, através da oferta do curso na modalidade subsequente, com maior demanda de público, maior concorrência de entrada, podendo-se aumentar o nível dos alunos, além de garantir melhor aprendizado.

Observou-se também que, atualmente (2017.1), o número de alunos matriculados no Curso Técnico em Aquicultura, com quatro semestres em andamento, é um total de 75, e alguns destes já concluíram todas as disciplinas e estão no estágio curricular, que é obrigatório, que também se constitui como elemento de retenção ou evasão no curso, ao ser ofertado esta maneira. Vale salientar que, em ambas as matrizes, o número de discentes que ingressaram por semestre corresponde a um total de 30 .

Os discentes que ingressaram na matriz curricular até o semestre 2014.1 apresentaram um coeficiente médio de rendimentos de 7,01, superior aos alunos que ingressaram a partir de 2014.2 , com a matriz unificada $(6,60)$.

A partir desses resultados, conclui-se que se pode realizar pequenos ajustes na matriz vigente, visando minimizar os índices de evasão escolar e rendimento dos discentes, além de ofertar o curso na modalidade subsequente, segundo os dados apresentados. De posse da 
implantação dessa nova modalidade de oferta, estudos futuros podem ser realizados visando novos dados de evasão escolar, rendimento dos discentes e êxito profissional para os futuros egressos.

\section{REFERÊNCIAS}

ARANTES, N. N. F. Trabalho e estudo: uma conciliação desafiante. 1. ed. Campina Grande: Realize Editora, 2012.

ARAÚJO, S. M. Sociologia: um olhar crítico. 1. ed. São Paulo: Contexto, 2013.

ASSAD, L. T.; BURSZTYN, M. Aquicultura sustentável. In: VALENTI, W. C.; POLI, R. C.; PEREIRA, J. A.; BORGHETTI, J. R. (Ed.). Aquicultura no Brasil: Bases para um desenvolvimento sustentável. Brasília: CNPq/Ministério da Ciência e Tecnologia, 2000.

BOIMARE, S. L'enfant et la peur d'apprendre. 1. ed. Paris: Dunod, 1999.

BOYD, C. E.; TUCKER, C. S. Pond Aquaculture Water Quality Management. 1. ed. Norwell, MA: Kluwer Academic Publishers, 1998. 700 p.

CATAPAN, A. H.; KASSICK, C. N.; OTERO, W. R. I. Metodologia para elaboração de matriz curricular: integração e transversalidade. Poiésis, v. 10, n. edição especial, p. 27-45, 2016.

FERNANDES, N. L. R. Projeto Político Pedagógico e Processo de Planejamento escolar. 1. ed. Fortaleza: SETEC/IFCE, 2013. 76 p.

FERREIRA, F. A. Fracasso e evasão escolar. 2013. Disponível em: <http://educador.brasilescola.com/ orientacao-escolar/fracasso-evasao-escolar.html> Acesso em: 20 mai. 2016.

FLEGEL, T. Review of disease transmission risks from prawn products exported for human consumption. Aquaculture, Elsevier, v. 290, n. 3-4, p. 179-189, 2009.

GERHARDT, T. E.; SILVEIRA, D. T. Métodos de Pesquisa. 1. ed. Porto Alegre: Editora da UFRGS, 2009. Coordenado pela Universidade Aberta do Brasil UAB/UFRGS e pelo Curso de Graduação Tecnológica, Planejamento e Gestão para o Desenvolvimento Rural da SEAD/UFRGS.
HYPOLITO, A. M. Currículo e projeto políticopedagógico: implicações na gestão e no trabalho docente. Cadernos de Educação, v. 18, n. 26, p. $11-26,2014$.

IFCE. Projeto Político Institucional/Instituto Federal de Educação, Ciência e Tecnologia do Ceará. Fortaleza, 2015. 86 p.

IFCE. Regulamento da Organização Didática ROD/Instituto Federal de Educação, Ciência e Tecnologia do Ceará. Fortaleza, 2015. 63 p.

IRELAND, V. E. Repensando a escola: um estudo sobre os desafios de aprender, ler e Escrever. 1. ed. Brasília: UNESCO, MEC/INEP, 2007.

KUBITZA, F. Aquicultura no brasil. Panorama da Aquicultura, v. 25, n. 1, p. 10-23, 2015.

LIBÂNEO, J. C. Organização e gestão escolar: teoria e prática. 5. ed. Goiânia: Editora alternativa, 2004.

LIGHTNER, D. V.; HASSON, K.; WHITE, B.; REDMAN, R. Experimental infection of western hemisphere penaeid shrimp with asian white spot syndrome virus and asian yellow head virus. Journal of aquatic animal health, Wiley Online Library, v. 10, n. 3, p. 271-281, 1998.

LUCK, H. Dimensões da Gestão Escolar e suas Competências. 1. ed. Curitiba: Positivo, 2008.

OSTRENSKY, A.; BORGHETTI, J. R.; SOTO, D. Aquiicultura no Brasil: o desafio é crescer. 1. ed. Brasília: Secretaria Especial de Aqüicultura e Pesca, 2008.

PADILHA, P. R. Planejamento dialógico: como construir o projeto político pedagógico da escola. 4 . ed. São Paulo: Cortez, 2003.

ROCZANSKI, M.; COSTA, S. W.; BOLL, M. G. A evolução da aquicultura no estado de santa catarina-brasil. In: Aquicultura Brasil 2000. Florianópolis: Anais do XI Simpósio Brasileiro de Aqüicultura, 2000. v. 11, p. 1-9.

SANTO, E. E. A análise da mudança na matriz curricular do curso de comunicação social numa instituição de ensino superior. In: XXIX Congresso Brasileiro de Ciências da Comunicação, Intercom. Brasília: Sociedade Brasileira de Estudos Interdisciplinares da Comunicação, 2006. p. 1-11. 
IMPACTO DA MATRIZ CURRICULAR VIGENTE PARA OS CURSOS TÉCNICOS EM AQUICULTURA DO IFCE: ESTUDO DE CASO NO CAMPUS ARACATI.

SANTOS, W. J. L.; ALVES, F. J. S. Política pública da qualidade na educação. Pensar contábil, v. 13, n. 52, p. 15-25, 2011.

SOARES, R. D. Evasão e repetência na rede federal de educação profissional. 1. ed. Maceió, Alagoas:

Programa Observatório da Educação - CAPES/Inep, 2013.

VASCONCELLOS, C. S. Planejamento: Projeto de Ensino Aprendizagem e Projeto Politico

Pedagógico. 15. ed. São Paulo: Libertad, 1996. 